\title{
PENGARUH KONSELING TERHADAP MINAT PASANGAN USIA SUBUR DALAM PEMILIHAN ALAT KONTRASEPSI IUD DAN IMPLANT
}

\author{
Henniwati ${ }^{1}$ \\ 1Kebidanan, Poltekkes Aceh, JIn. Islamic Center PB. Beuramo \\ email :henniwati796@yahoo.com
}

\begin{abstract}
Background: Impland and IUD are the lowest number 2 and 3 contraceptives used by couples of childbearing age at Langsa Barat Community Health Center. Long-term contraceptive method (MKJP) is the best choice for couples of childbearing age to space their pregnancies. Providing counseling to couples of childbearing age is very influential in increasing the knowledge and interest of PUS in MKJP selection.

Purpose: This study was to determine the effect of counseling on the interest of fertile age couples (PUS) in the selection of impland contraceptives and the IUD at Langsa Barat Public Health Center.

Methods: This study used a quasi-experimental study with a pretest-posttest control group design approach. The sampling technique used random sampling technique, the number of samples in this study were 38 couples of childbearing age

Results: The study was found in the intervention group who were interested in using contraceptives as many as 17 (89.5\%). 9 people (47.4\%) were interested in the control group. The results of the paired sample T Test analysis showed that there was no effect of counseling on the interest of fertile age couples in choosing impland contraceptives and IUDs.

Conclusion: There is no effect of counseling on the interest of fertile aged couples in choosing contraceptives.

Suggestion: It is hoped that the next researcher can conduct further research on the method of video visual counseling in providing family planning counseling to fertile elderly couples.
\end{abstract}

Keywords: Counseling, Interest of EFA

\section{ABSTRAK}

Latar Belakang : Impland dan AKDR merupakan alat kontrasepsi nomor 2 dan 3 terendah yang digunakan pasangan usia subur di Puskesmas Langsa Barat. metode kontrasepsi jangka panjang (MKJP) merupakan pilihan terbaik bagi pasangan usia subur untuk menjarangkan kehamilannya. pemberian konseling kepada pasangan usia subur sangat berpengaruh untuk meningkatkan pengetahuan dan minat PUS dalam pemilihan MKJP.

Tujuan : Penelitian ini untuk mengetahui pengaruh konseling terhadap minat pasangan usia subur (PUS) dalam pemilihan alat kontrasepsi Impland dan AKDR di Puskesmas Langsa Barat.

Metode : Penelitian ini menggunakan quasi eksperimen dengan pendekatan desain control group pretestposttest. tehnik pengambilan sampel menggunaka Tehnik Random Sampling, jumlah sampel pada penelitian ini yaitu 38 pasangan usia subur

Hasil: Penelitian didapat pada kelompok intervensi yang berminat menggunakan alat kontrasepsi sebanyak $17(89.5 \%)$. pada kelompok kontrol yang berminat sebnayak 9 orang $(47,4 \%)$. hasil analisis paired sampel T Test menunjukan tidak ada pengaruh konseling terhadap minat pasangan usia subur dalam memilih kontrasepsi impland dan AKDR. kontrasepsi.

Kesimpulan : Tidak ada pengeruh konseling terhadap minat pasangan usia subur dalam pemilihan alat

Saran : Diharapkan bagi peneliti selanjutnya dapat melakukan penelitian lebih lanjut tentang metode konseling video visual dalam pemberian konsiling KB pada pasanagan usisa subur.

Kata Kunci : Konseling, Minat PUS, IUD dan Implant

PENDAHULUAN 
Untuk meningkatkan angka keberhasilan suatu pengembangan yang berkelanjutan dalam bidang kesehatan dapat dilihat dari tingginya angka kelahiran dan kematian. peningkatan jumlah penduduk, serta pengaruh lingkungan sangat menentukan kualitas generasi mendatang untuk keberhasilan pembangunan (BKKBN, 2016).

Peraturan Perundang-undangan Nomor 52 Tahun 2009 terhadap tingginyajumlah penduduk dan kesehatan Keluarga, menyebutkan bahwa kependudukan harus menjadi titik sentral dalam pembangunan berkelanjutan di Indonesia yang memiliki angka perkiraan jumlah total anak yang dilahirkan (fertilisasi)atau Total Fertility Rate (TFR) menurut SDKI 2017, di Indonesia adalah 2,4 dimana TFR lebih rendah dari tahun 2012 yaitu 4,6. Hasil tersebut belum mencapai Renstra 2015-2019 yakni 2,3. Untuk Aceh, Angka Fertilitas Jumlah (TFR) adalah 2,7 masih diatas angka Nasional (SDKI, 2017).

Survei Demografi Kesehatan Indonesiamendapatkan pasangan usia subur yang tidak ber KB, usia subur 15-49 tahun yang pada saat pendataan didapati $55 \%$ ingin menjadi aseptor KBsedangkan $41 \%$ menolak menjadi aseptor KB. Sehingga perlu dilakukan penyuluhan kepada pasangan usia subur yang belum menjadi aseptor untuk memilih alat kontrasepsi yang di gunakan untuk masa yang akan datang (SDKI, 2017).

Upaya pencegahan peningkatanjumlah penduduk, Pemerintah membuat rancangan metode kontrasepsi Kontraspsi Jangka Panjang (MKJP) menjadialat kontrasepsi dengan masa pemakaian yang cukup lama. kontrasepsi ini sangat efektif digunakan pada ibu pasca salin sectio cesaria, alat kontrasepsi dalam rahim atau AKDRefektivitasnya dapat bertahan selama 5-10 tahun, sedangkan alat kontrasepsi bawah kulit atau implant dengan masa berlaku 3 tahun (Manurung, 2013).

Notoatmodjo, 2012 dalam Teori Health Belief Model (HBM) Lewin (1954), sedikitnya peminatan masyarakat terhadap metode kontrasepsi jangka panjang (MKJP), terlihat dari rendahnya minat masyarakat terhadap penggunaan alat kontasepsi tersebut. Pola fikir masyarakat belum memahami betul keuntungandan kerugiannya. Pemikiran dari masyarakat dapat terpengaruh berdasarkan umur, jumlah paritas, tingkat pendidikan, tempat tinggal, dan pelayanan kesehatan. (Notoatmodjo, 2012)

Akan tetapi masih terdapat dua sasaran yang menjadi perhatian bersama sesuai target yang telah disepakati dalam integritas masyarakat dan pembangunan, dimana yang pertama sekali dilihat bahwa masyarakat bukan merupakan sasaran yang pasif tetapi sebagai yang aktif sehingga dapat terlibat langsung dalam meningkatkan pembangunan. Kedua, jika masyarakat terlibat secara aktif dalam meningkatkan pembangunan, maka harus ada upaya peningkatan kerjasama dalam pembangunan. (BKKBN, 2016).

Terpaparnya informasi dari media masa terhadap penggunaan MKJP, dari promosi dan edukasi dapat menimbulkan perubahan prilaku manusia, sehingga mindset masyarakat terhadap kontasepsi tersebut terpola pada pikiran yang melibatkan otak kiri dan kanan. Promosi yang diberikan dengan menggunakan baliho, dan poster dapat munumbuhkan minat yang sangat besar terhadap pengambilan keputusan untuk bergabung dalam penggunaan alat kontasepsi jangka panjang (MKJP) (Nurdiana, 2014)

Informasi yang diterima saat pemberian pelayanan kesehatan khususnya pelayanan keluarga berencana (KB) pada pasangan usia subur (PUS). Pemberian informasi dari petugas dapat membantu dalam melakukan keputusan dan mengarahkan jenis kontrasepsi apa yang cocok untuk digunakannya. Untuk mensukseskan program keluarga berencana, pemerintah melakukan peningkatan pelatihan bagi para bidan agar mampu memberikan pelayanan berbagai metode kontrasepsi.(Siswanto, 2010)

Data di Puskesmas Puskesmas Langsa Barat dari 5.791 PUS yang merupakan akseptor KB aktif sebanyak 3.758 orang, dengan rincian kontrasepsi suntik $1.651(44 \%)$, pil $1.685(45 \%)$, kondom $310(8,3 \%)$, Implant $19(0,6 \%)$, IUD 33 $(0,9 \%)$, MOW $9(0,3 \%)$, MOP $9(0,0 \%)$.

Puskesmas Langsa Barat merupakan data terendah dalam penggunakan alat kontrasepsi jangka panjang dari pada Puskesmas lainnya di Kota Langsa

Tujuan penelitian ini untuk mengetahui pengaruh konseling terhadap minat pasangan usia subur (PUS) dalam pemilihan alat kontrasepsi Implan dan AKDR di Puskesmas Langsa Barat

\section{METODE PENELITIAN}

Jenis penelitian ini adalah Analitik,dengan mengunakan quasi eksperimen dengan pendekatan desain control group pretest-posttest, yaitu pengamatan dilakukan pada saat pre dan post, dilakukan sebelum dan sesudah intervensi.

Penelitian ini dilakukan di Puskesmas Langsa Barat dengan mengelompokkan pasangan usia subur (PUS) yang Belum pernah menjadi aseptor KB. Tehnik pengambilan sampel dengan menggunakan rumus Slovin dengan tehnik random sampel. subjek dibutuhkan sebanyak 38 sampel, 
dengan jumlah perkelompok sebanyak 19 orang. subjek dibagi menjadi 2 kelompok, yaitu kelompok intervensi diberikan perlakuan berupa konseling dan kelompok control tidak diberikan konseling.

Jenis data yang digunakan yaitu data primer. pengumpulan data dibantu oleh enumerator. peneliti denganbantuan enumerator melakukan door to door untuk melakukan konseling $\mathrm{Kb}$.

Intrumen pada penelitian ini menggunakan lembar observasi untuk melihat sejauh mana minat PUS dalam pemilihat alat kontrasepsi jangka panjang

Analisi univariat digunakan untuk untuk mendeskripsikan kataristik responden dan minat PUS dalam pemilihat alat kontrasepsi. analisis bivariat untuk melihat sejauh mana pengaruh dari variabel independen terhadap variabel dependen. analisis yang digunakan yaitu paired sampel t test.

HASIL PENELITIAN

Analisis Univariat

Umur Responden

Tabel 1.

Distribusi Frekuensi Responden

Berdasarkan Umur Di Wilayah Kerja

Puskesmas Langsa Barat

\begin{tabular}{lcccc}
\hline Karakteristik & \multicolumn{2}{c}{$\begin{array}{c}\text { Kelompok } \\
\text { Perlakuan }\end{array}$} & $\begin{array}{c}\text { Kelompok } \\
\text { Kontrol }\end{array}$ \\
\cline { 2 - 5 } & $\mathbf{n}$ & $\%$ & $\mathbf{n}$ & $\%$ \\
\hline Umur & & & & \\
$<$ 20 Tahun & 3 & 15,8 & 0 & 0 \\
20 - 30 Tahun & 14 & 73,7 & 17 & 89,5 \\
$>$ 30 Tahun & 2 & 10,5 & 2 & Tabel 10,5 \\
Total & 19 & & 19 & \\
\hline
\end{tabular}

Berdasarkan tabel diatas dapat dilihat bahwa karakteristik umur responden dalam penelitian ini untuk kelompok perlakuan mayoritasumur $20-30$ tahun sebanyak 14 responden $(73,7 \%$ ), sedangkan kelompok kontrol mayoritas umur 20 - 30 tahun sebanyak 17 responden ( 89,5\%).

\section{Paritas Responden}

Berdasarkan tabel di bawah dapat dilihat bahwakarakteristikparitas kelompok perlakuan mayoritas multipara sebanyak 9 responden $(47,4 \%)$,begitu pula kelompok kontrol sebanyak 8 responden $(42,4 \%)$.

Tabel 2.

Distribusi Responden Berdasarkan Paritas Di Wilayah KerjaPuskesmas Langsa Barat

\begin{tabular}{lllll}
\hline \multirow{2}{*}{$\begin{array}{l}\text { Karakteristik } \\
\text { Pataritas }\end{array}$} & \multicolumn{4}{c}{ Intervensi kontrol } \\
\cline { 2 - 5 } & $\mathbf{n}$ & $\%$ & $\mathbf{n}$ & $\%$ \\
\hline Primipara & 4 & 21,1 & 5 & 26,3 \\
Multipara & 9 & 47,4 & 8 & 42,1 \\
Grande Multipara & 6 & 31,6 & 6 & 31,6 \\
Total & 19 & & 19 & \\
\hline
\end{tabular}

Minat Responden

Tabel 3.

Distribusi Frekuensi Minat Terhadap Alat

Kontrasepsi Implant dan AKDRSebelum dan

Sesudah diberikan Konseling KB dan Tidak Diberikan Konseling Di Wilayah Kerja Puskesmas Langsa Barat

\begin{tabular}{lcccc}
\hline & \multicolumn{4}{c}{ Kelompok } \\
\cline { 2 - 5 } \multicolumn{1}{c}{ Minat } & \multicolumn{2}{c}{ Intervensi } & \multicolumn{2}{c}{ Kontrol } \\
\cline { 2 - 5 } & \multicolumn{2}{c}{$(\mathbf{n = 1 9 )}$} & \multicolumn{2}{c}{$(\mathbf{n = 1 9 )}$} \\
\cline { 2 - 5 } & $\boldsymbol{f}$ & $\%$ & \multicolumn{1}{c}{$\%$} & $\%$ \\
\hline $\begin{array}{l}\text { Pre Test } \\
\text { Minat }\end{array}$ & 10 & 52.6 & 6 & 31,6 \\
Tidak & 9 & 47.4 & 13 & $68^{\prime} 4$ \\
Berminat & & & & \\
Post Test & & & 9 & 47,4 \\
Minat & 17 & 89.5 & 9 & 52,6 \\
Tidak & 2 & 10.5 & 10 & \\
Berminat & 2 & & & \\
\hline
\end{tabular}

Dapat disimpulkan bahwa jumlah persentase kelompok perlakuan yang berminat memilih alat kontrasepsi implan dan AKDR sebelum diberikan perlakuan sebanyak 10 responden (52.6\%) dan sesudah diberikan perlakuan meningkat menjadi 17 responden $(89,5 \%)$, sedangkan pada kelompok kontrol persentase responden yang berminat memilih alat kontrasepsi implan dan AKDR sebelum perlakuan sebanyak 6 responden dan sesudah diberikan perlakuan hanya bertambah sedikit menjadi 9 responden $(42,1 \%)$ yang berminat memilih alat kontrasepsi implan dan AKDR.

\section{Analisis Bivariat}

Dari hasil tabel dapat disimpulkan bahwa adanya peningkatan persentase minat, sebesar $18,4 \%$.

Tabel 4.

Minat Terhadap Pemilihat Alat Kontrasepsi Perubahan Minat Terhadap Alat Kontrasepsi Implan dan AKDR Sebelumdan Sesudah 


\section{Diberikan Konseling KB Di Wilayah Kerja Puskesmas Langsa Barat}

\begin{tabular}{|c|c|c|c|}
\hline \multirow[b]{2}{*}{ Minat } & \multicolumn{2}{|c|}{ Kelompok } & \multirow{2}{*}{$\begin{array}{c}\text { Nilai } \\
\mathbf{P} \\
\text { value }\end{array}$} \\
\hline & $\begin{array}{c}\text { Perlakuan } \\
(n=19)\end{array}$ & $\begin{array}{c}\text { Kontrol } \\
(n=19)\end{array}$ & \\
\hline \multicolumn{4}{|l|}{ Pre Test } \\
\hline $\mathrm{Ya}$ & 10 & 6 & \\
\hline Tidak & 9 & 13 & \\
\hline Total & 19 & 19 & \\
\hline Post Test & & & \\
\hline Minat & 17 & 9 & \\
\hline Tidak & 2 & 10 & \\
\hline Total & 19 & 19 & \\
\hline $\begin{array}{l}\% \text { Peningkatan } \\
\text { Minat }\end{array}$ & $7(18,4 \%)$ & $3(7,9 \%)$ & 0,135 \\
\hline
\end{tabular}

\section{PEMBAHASAN}

Dari hasil penelitian dapat disimpulkan bahwa minat aseptor dalam memilih alat kontrasepsi Implan dan AKDR sebelum dan sesudah perlakuan menunjukkan tidak ada pengaruh dimana hasil yang didapati adalah 0,135. (P>0,05). penelitian ini didapati perbedaan minat setelah dilakukan konseling KB dengan menggunakan video.

Hasil penelitian ini sesuai dengan penelitian yang dilakukan oleh Nurdiana, dkk, 2014, berjudul Pengembangan Model Konseling KB Berbasis Video di Kabupaten Karawang Tahun 2014. Hasil menunjukkan bahwa Terpaparnya informasi dari media masa terhadap penggunaan MKJP, dari promosi dan edukasi dapat menimbulkan perubahan prilaku manusia, sehingga mindset masyarakat terhadap kontasepsi tersebut terpola pada pikiran yang melibatkan otak kiri dan kanan. Promosi yang diberikan dengan menggunakan baliho, dan poster dapat munumbuhkan minat yang sangat besar terhadap pengambilan keputusan untuk bergabung dalam penggunaan alat kontasepsi jangka panjang (MKJP) (Nurdiana, 2014)

Penelitian ini tidak jauh berbeda dengan penelitian yang dilakukan oleh Meta, dkk, dimana jumlah paritas berpengaruh terhadap memilih alat kontrasepsi di Puskesmas Banguntapan II Bantul Yogyakarta. hasil penelitian juga menunjukkan ada pengaruh konseling $\mathrm{KB}$ terhadap tingkat pengetahuan akseptor pasca persalinan (Meta Kaporina, 2016)

Penelitian ini berbeda dengan penelitian Mulyani (2018), hasil penelitian didapat ada pengaruh konseling kontrasepsi dengan menggunakan leaflet terhadap pemilihan MKJP IUD di Puskesmas Gamping I Sleman.
Informasi yang diberikan kepada masyarakat sangatlah penting dikarenakan permasalahan kontrasepsi khususnya metode kontrasepsi jangka panjang belum begitu dipahami manfaatnya sehingga masyarakat enggan untuk memilih kontrasepsi tersebut, konseling yang diberikan oleh petugas kesehatan merupakan cara yang paling tepat selain dari mempromosikan dengan mengunakan media, baleho maupun poster sehingga, akseptor mantap dalam mengambil keputusan terhadap kontrasepsi yang akan digunakannya. (Pemmi Sinaga, 2016)

Hasil ini menunjukan bahwa secara rata-rata terdapat perbedaan sebelum dan sesudah dilakukannya uji akan tetapi tidak didapati perbedaan minat sebelum dan sesudah dilakukannya konseling. Hal ini dikarenakan pengambilan keputusan akseptor terhadap pilihannya tidak dapat diintervensi. Bisa saja responden sebelumnya memang sudah akan memilih alat kontrasepsi implan dan AKDR sebelum dilakukannya konseling. Sehingga tidak merubah keputusan akseptor walaupun sebelum atau sesudah diberikan konseling.

Asumsi peneliti berdasarkan hasil penelitian ini dengan menggunakan media maka responden dapat lebih fokus dalam menerima informasi dan dapat melihat langsung apa yang ingin disampaikan tentang alat kontrasepsi implant dan AKDR. Responden yang tidak berpendidikan tinggipun dapat dengan mudah paham dan mampu mengingat apa yang mereka lihat secara langsung. Dengan bertambahnya informasi dan pemahaman responden dapat merubah minat mereka dalam memilih alat kontrasepsi implant dan AKDR.

\section{KESIMPULAN}

Tidak ada pengaruh yang signifikan terhadap minat PUS dalam memilih alat kontrasepsi implan dan AKDR antara kelompok intervensi yang diberikan perlakuan dengan kelompok kontrol yang tidak diberikan perlakuan. Konseling yang diberikan dengan menggunakan lembar balik yang berikan informasi tantang IUD dan implant. konseling diberikan 1 kali dengan durasi 20-30 menit.

\section{SARAN}

Diharapkan kepada Petugas kesehatan untuk dapat lebih meningkatkan promosi dengan metode selain lembar balik, dan keterampilan serta kemampuan serta lebih aktif melakukan pendekatan kepada akseptor KB sehingga dapat memotivasi pasangan usia subur untuk ikut akseptor KB implant dan AKDR.Meningkatkan informasi dan pengetahuan PUS dengan metode promosi yang 
laiinya sehingga mereka dapat menjadi kader dalam meningkatkan minat PUS yang belum ber KB memilih implant dan AKDR sebagai alat kontrasepsi Jangka Panjang Bagi institusi pendidikan sebagai bahan informasi juga referensi bagi pengembangan ilmu pengetahuan mengenai alat kontrasepsi implant dan AKDR.Peneliti diharapkan dapat menjadi motivator dalam pengembangan informasi dan meningkatkan pengetahuan tentang alat kontrasepsi implan dan AKDR.

\section{DAFTAR PUSTAKA}

BKKBN, 2016, Rencana Strategis Badan Kependudukan Dan Keluarga Berencana Nasional tahun 2015-2019

Manurung, Suryani, 2013, Model Pengambilan Keputusan Meningkatkan Akseptor Keluarga Berencana Metode Kontrasepsi Jangka Panjang Tahun 2013

Meta Kaporina, 2016, Hubungan Paritas Terhadap Minat Penggunaan Alat Kontrasepsi Di
Puskesmas Banguntapan II Bantul Yogyakarta Tahun 2016

Mulyani Hari. 2018. Pengaruh Konseling Kontrasepsi Terhadap Minat Pemilihan MKJP IUD Di Puskesmas Gamping I Sleman.

Notoatmodjo, 2012, IImu Perilaku Kesehatan. Jakarta : PT. Rineka Cipta

Nurdiana, dkk, 2014, Pengembangan Model Konseling KB Berbasis Vidio di Kabupaten Karawang Tahun 2014

Pemmi Sinaga, 2016, Pengaruh Konseling Petugas Kesehatan Terhadap Pemilihan Metode Kontrasepsi Jangka Panjang (MKJP) Di Puskesmas Padang Bulan Selayang II Kecamatan Medan Selayang Tahun 2016

SDKI, 2017, Survey Demografi Dan Kesehatan Indonesia (SDKI)

Siswanto, 2010, Keluarga Berencana dan Kesehatan Reproduksi. Pustaka Pelajar, Yogyakarta 